\title{
Supplement: Eddy permitting simulations of freshwater injection from major Northern hemisphere outlets during the last deglacial
}

Ryan Love ${ }^{1}$, Heather Andres ${ }^{1}$, Alan Condron$^{2}$, and Lev Tarasov ${ }^{1}$

1 Department of Physics and Physical Oceanography, Memorial University of Newfoundland, St. John's, Newfoundland, Canada

${ }^{2}$ Geology \& Geophysics, Woods Hole Oceanographic Institution , Woods Hole, Massachusetts, $\underline{\mathrm{USA}}$

February 25, 2021 


\section{Supplemental Figures}

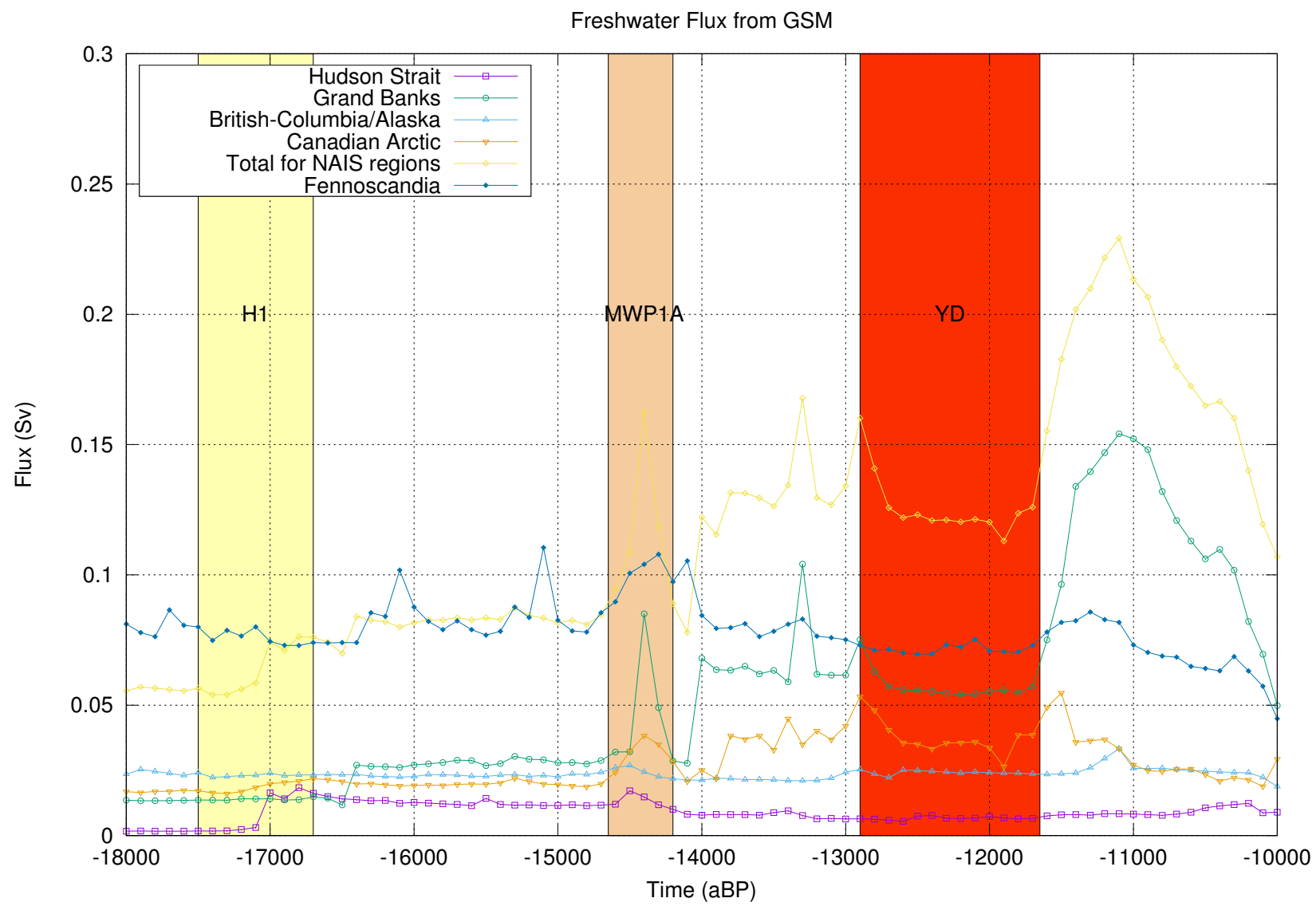

Figure S1: Water flux from land into the ocean as calculated by the GSM of Tarasov et al. 2012]. Included in the values are meltwater, precipitation (self consistent with the GSM), and ice calving. The river routing scheme used internally by the GSM includes subgrid parametrizations to aid in the accuracy of drainage basin gateways. 


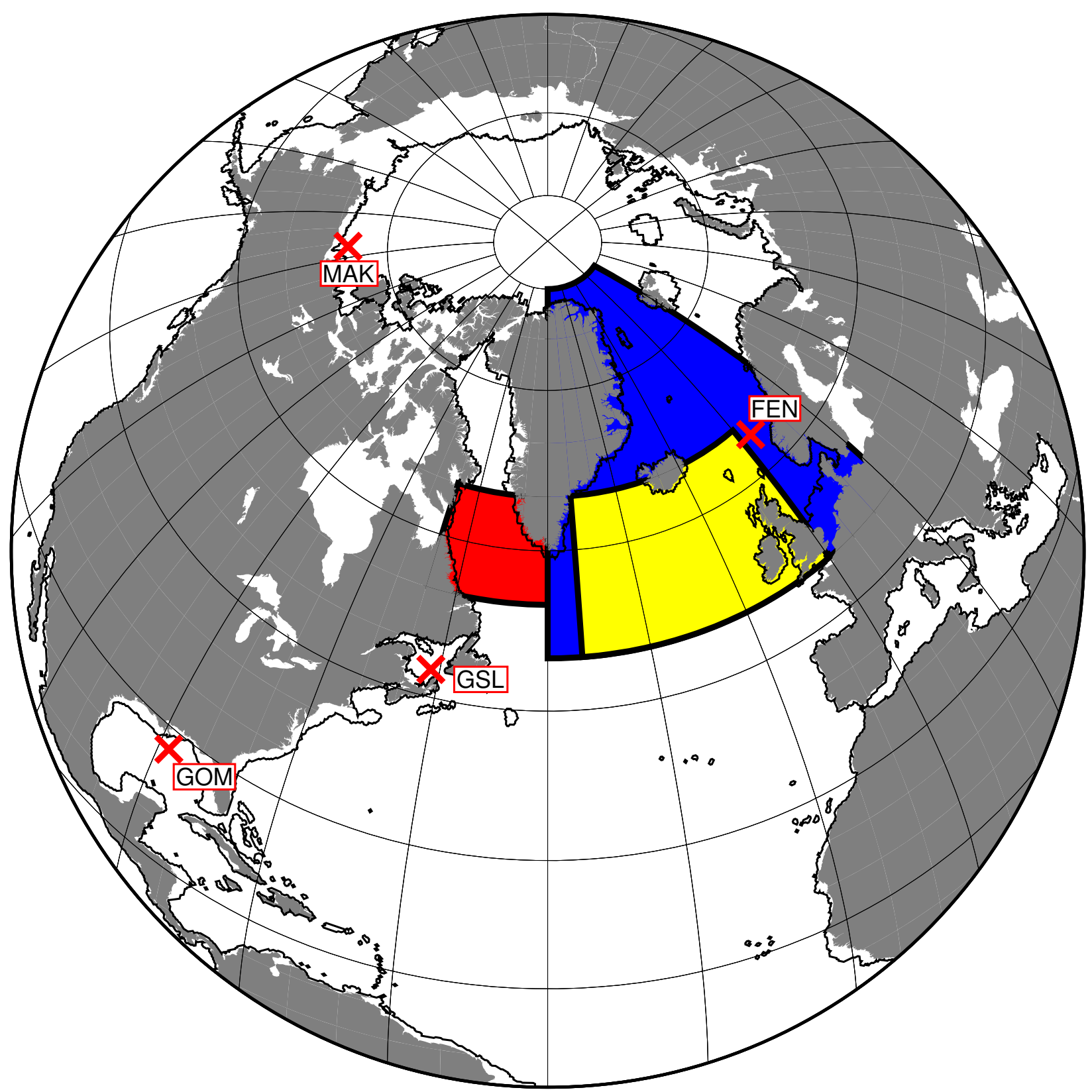

Figure S2: Freshwater injection locations used, short form names used for each location are annotated. Each of the averaging regions are highlighted with red for the Labrador Sea region, blue for the GIN seas region, and yellow for the North Atlantic deep water formation region. Present day land surface is drawn in gray while the closed Bering Strait coastline is drawn in black. 


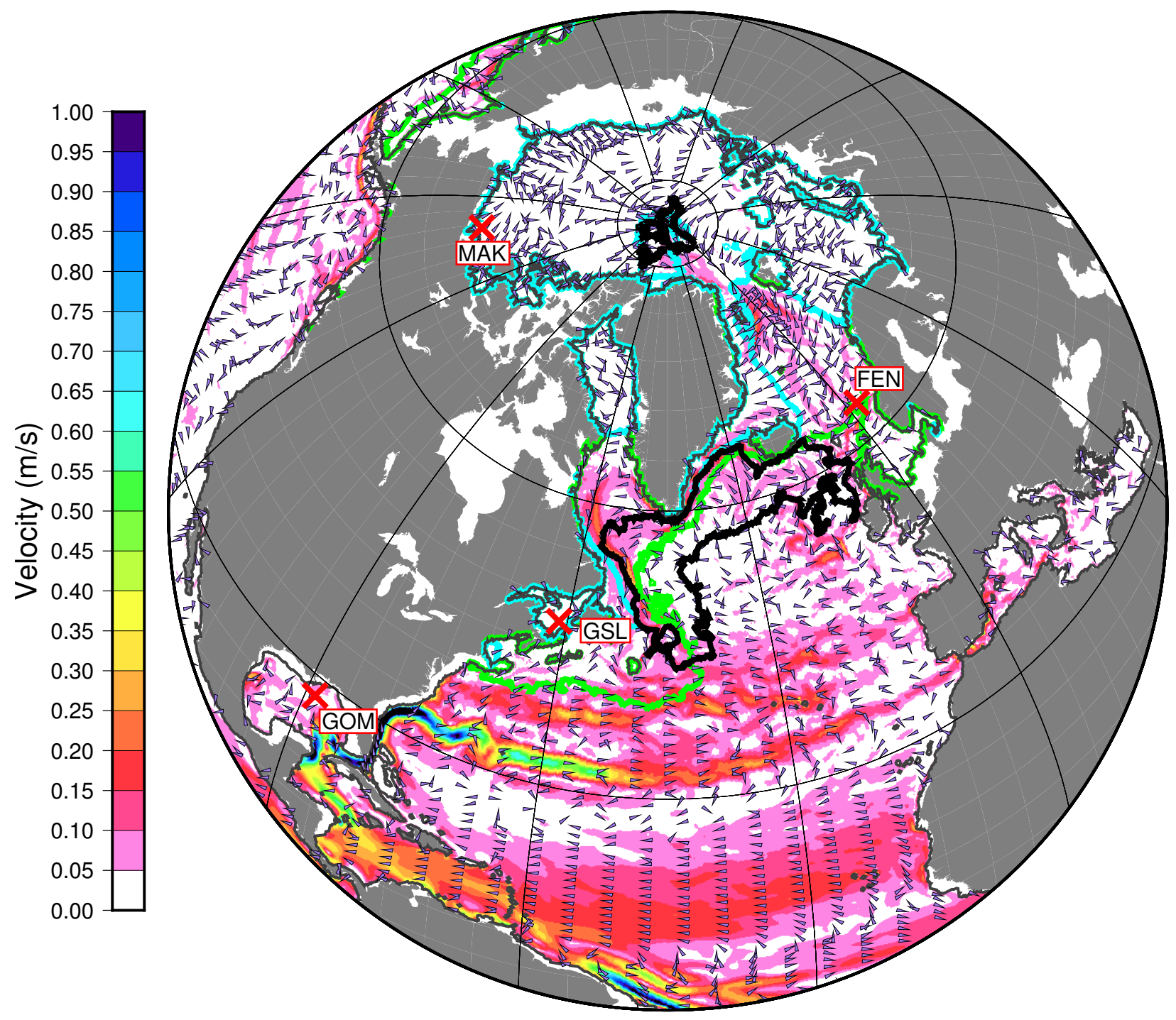

Figure S3: Average sea surface velocity for the last 5 years of our CBS Control run with arrows denoting the direction. Present day land-sea mask is shown in light grey while simulation land-sea mask is contoured in a darker shade of grey. The cyan and green contours denotes the time minimum and maximum sea ice extent respectively, of at least $15 \%$ sea ice coverage calculated over the last 5 years of the simulation. When comparing the sea ice maximal extent to the mixed layer depth shown in S5 (for the OBS case) and black contour, denoting $1000 \mathrm{~m}$ mixed layer depth, in the current plot we see the mixing is just off the outer limit of the sea ice maximum. The arrows denoting direction are shown at a lesser density than the native grid to aid in visualization. 


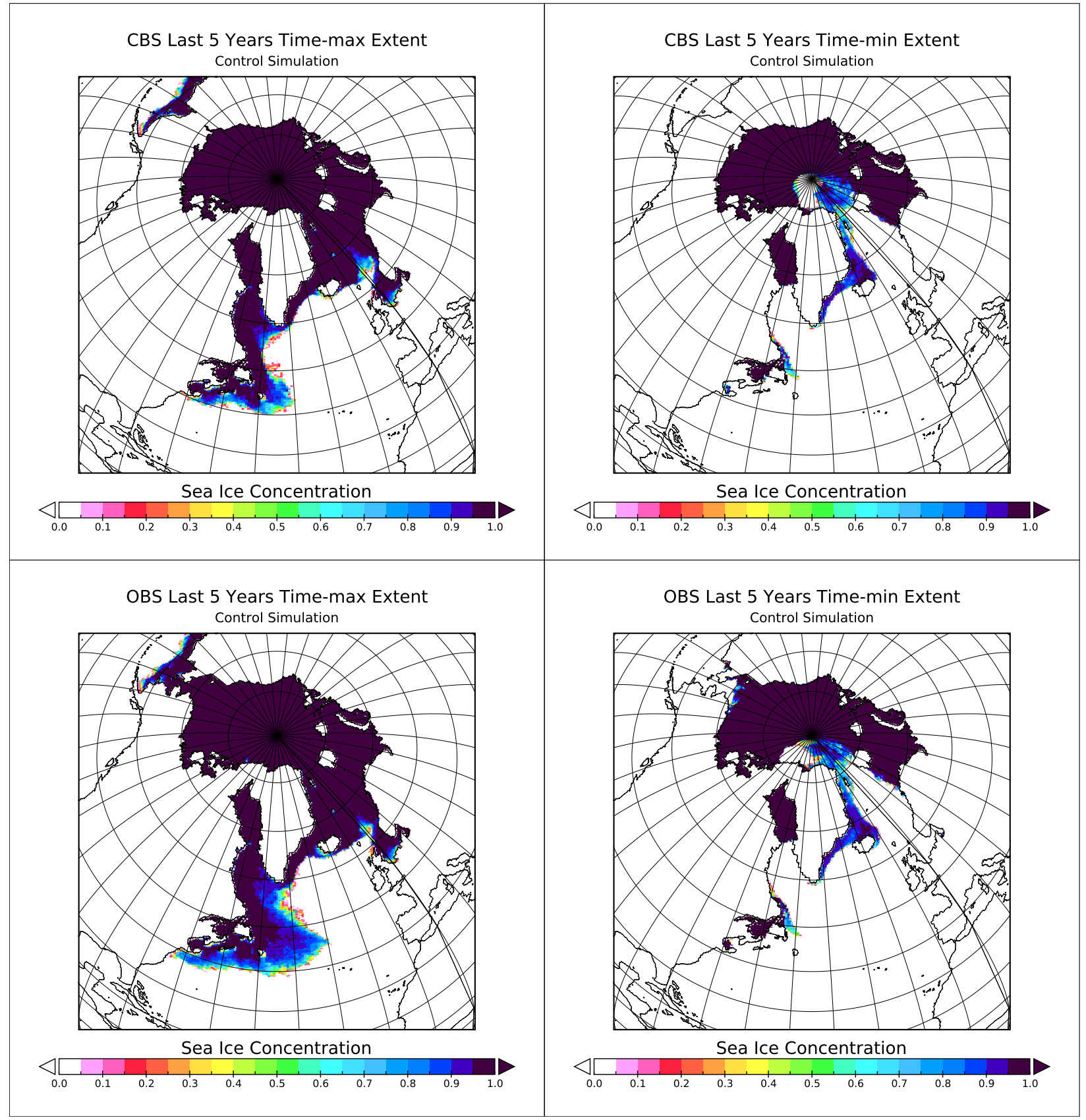

Figure S4: Sea ice minimal and maximal extent for both the open and closed Bering Strait control simulations. Minimum/maximum field generated as the time minimum/maximum from the last 5 years of simulation data for each run (whose duration is approximately 30 simulation years each). 


\section{Mixed Layer Depth - Last Year Average OBS Control}

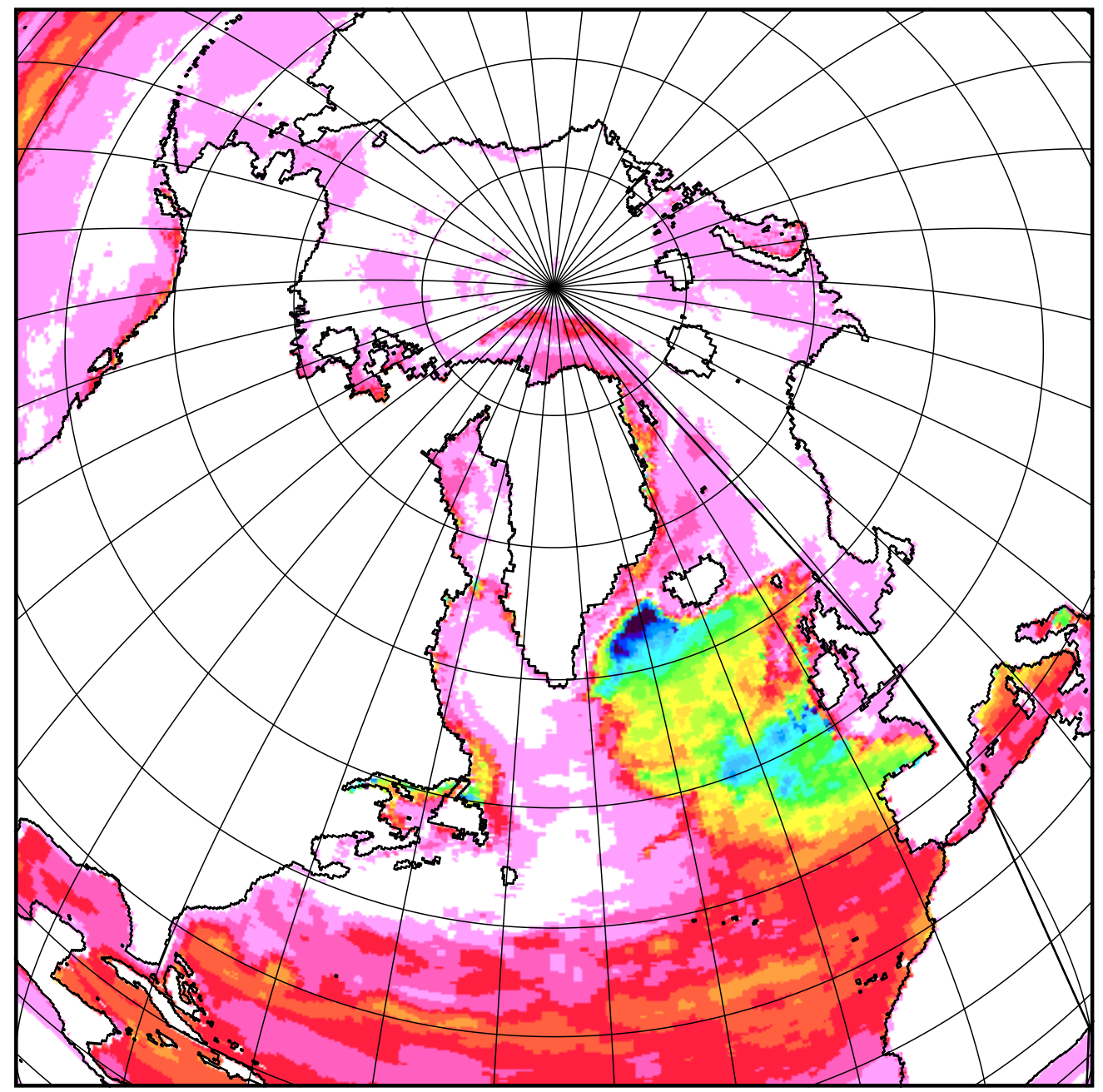

Mixed Layer Depth (m)

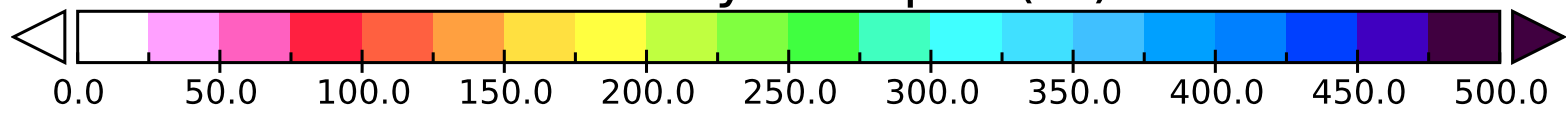

Figure S5: Mixed layer depth in the North Atlantic from the last year of our control simulation. The most significant region of mixing is between $-40 \mathrm{E}$ to $0 \mathrm{E}, 50 \mathrm{~N}$ to $65 \mathrm{~N}$. This is the region which we examine the salinity anomaly to evaluate the impact of each of our injection scenarios. 


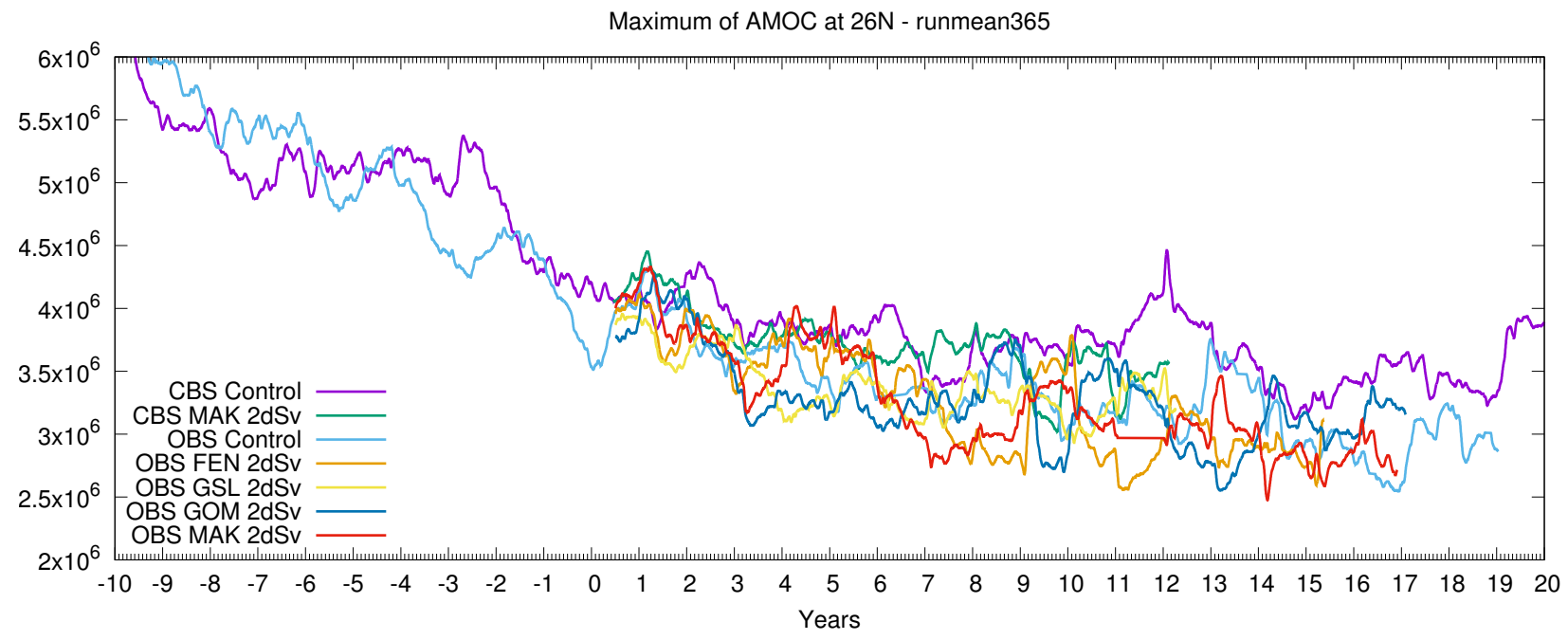

Figure S6: AMOC calculated as the maximum of the meridional overturning stream function at $26 \mathrm{~N}$, to coincide with the RAPID array, at depths below $700 \mathrm{~m}$. Timeseries shown are 1 year running means where year 0 is when glacial runoff is introduced into the model. The standard deviation of this time series, calculated annually, ranges between 1-1.5Sv. 


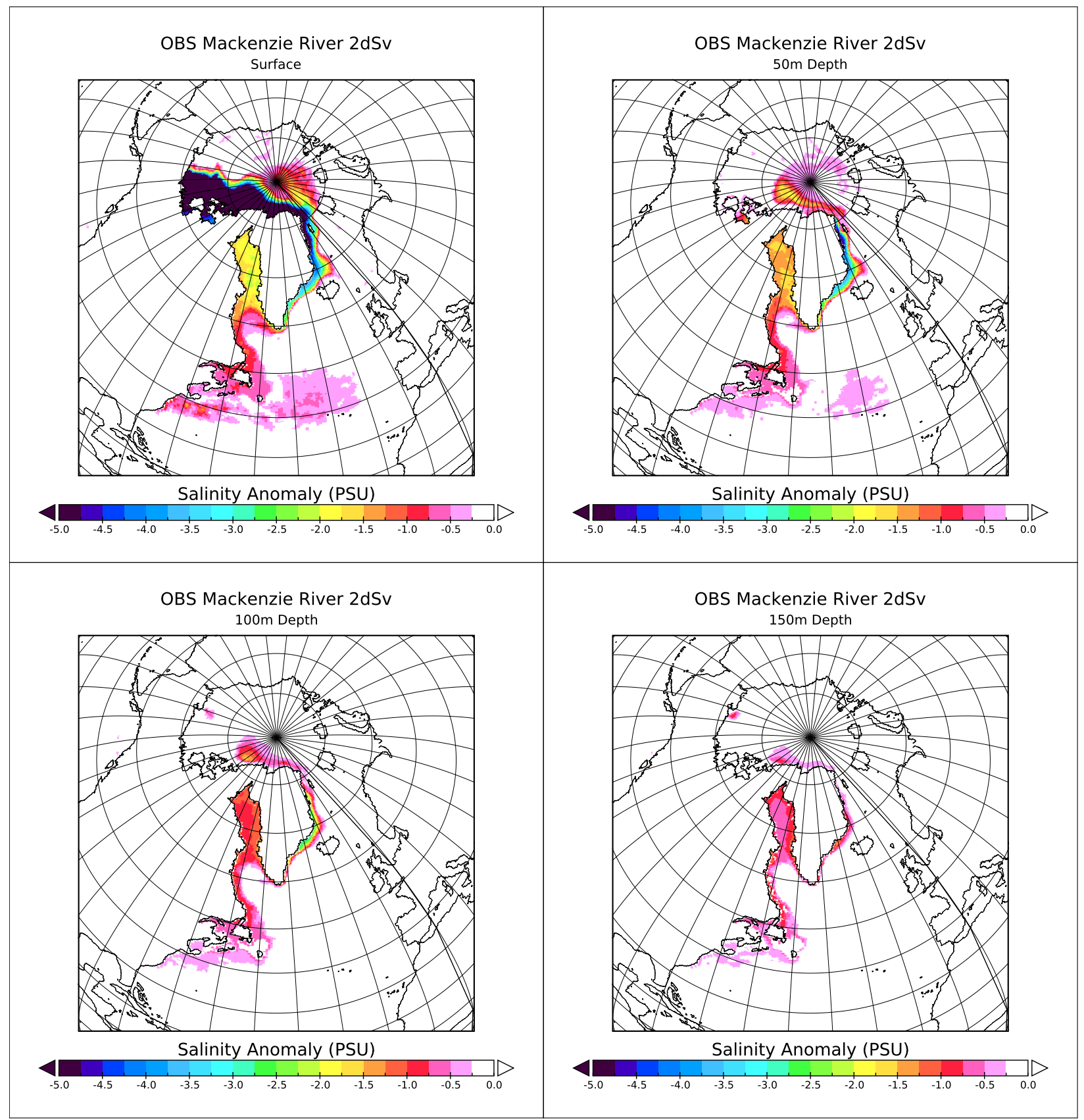

Figure S7: Salinity anomaly distribution at a selection of depths for the Open Bering Strait Mackenzie River 2dSv continual injection scenario. This distribution is the average of the anomaly field over the last 5 years of model integration. 


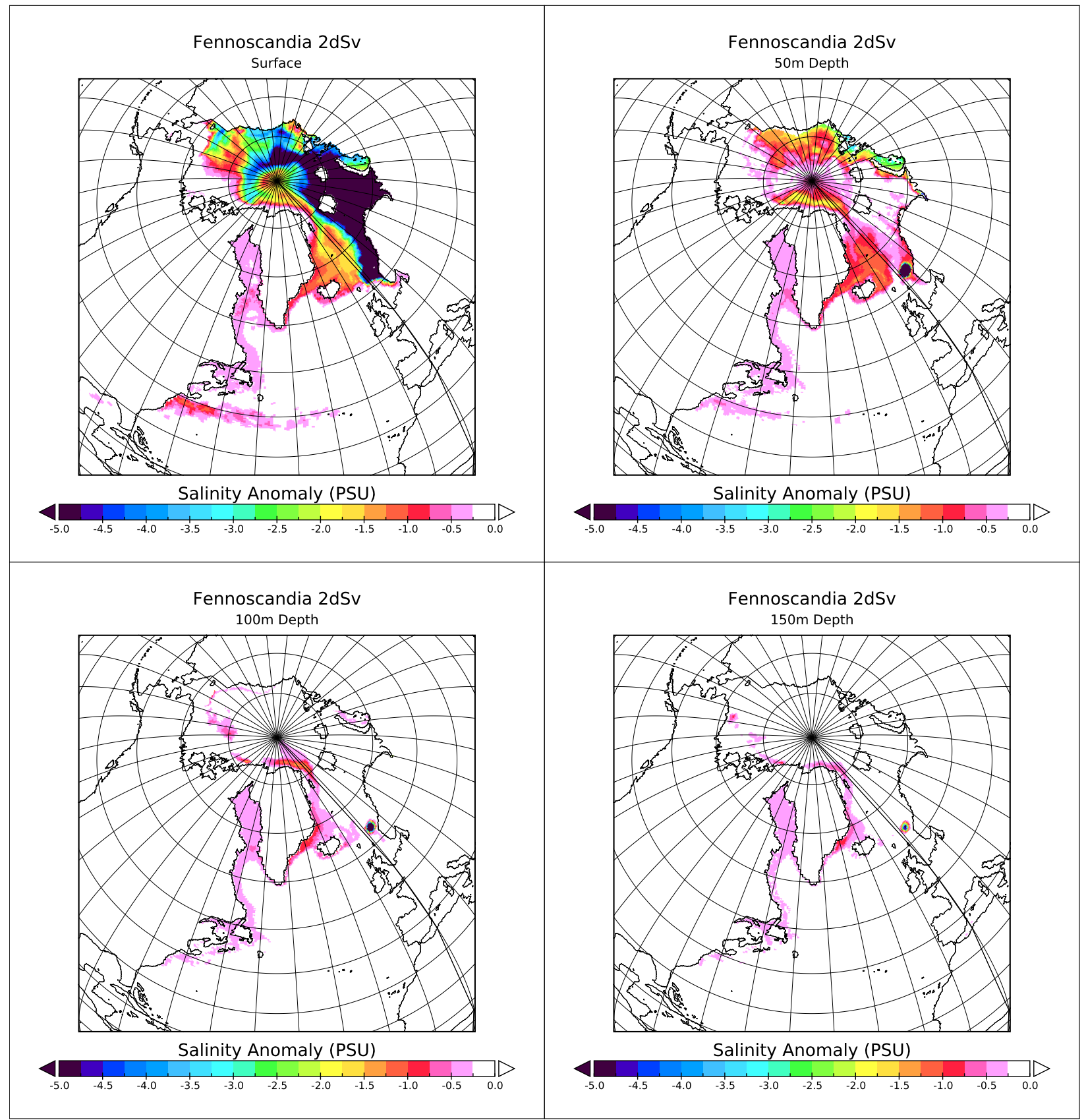

Figure S8: Salinity anomaly distribution at a selection of depths for the Open Bering Strait Fennoscandia 2dSv continual injection scenario. This distribution is the average of the anomaly field over the last 5 years of model integration. 


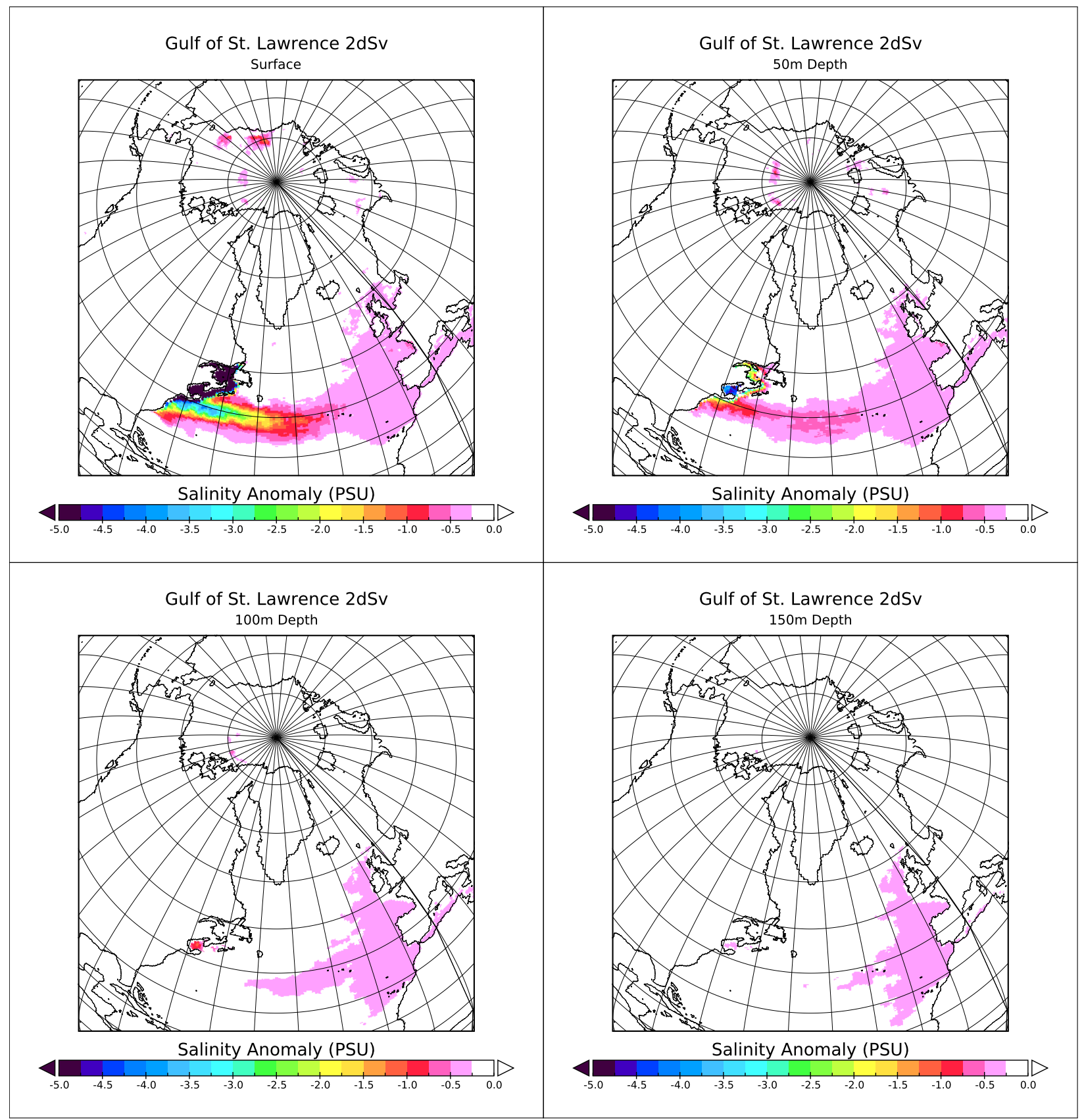

Figure S9: Salinity anomaly distribution at a selection of depths for the Open Bering Strait Gulf of St. Lawrence $2 \mathrm{dSv}$ continual injection scenario. This distribution is the average of the anomaly field over the last 5 years of model integration. 


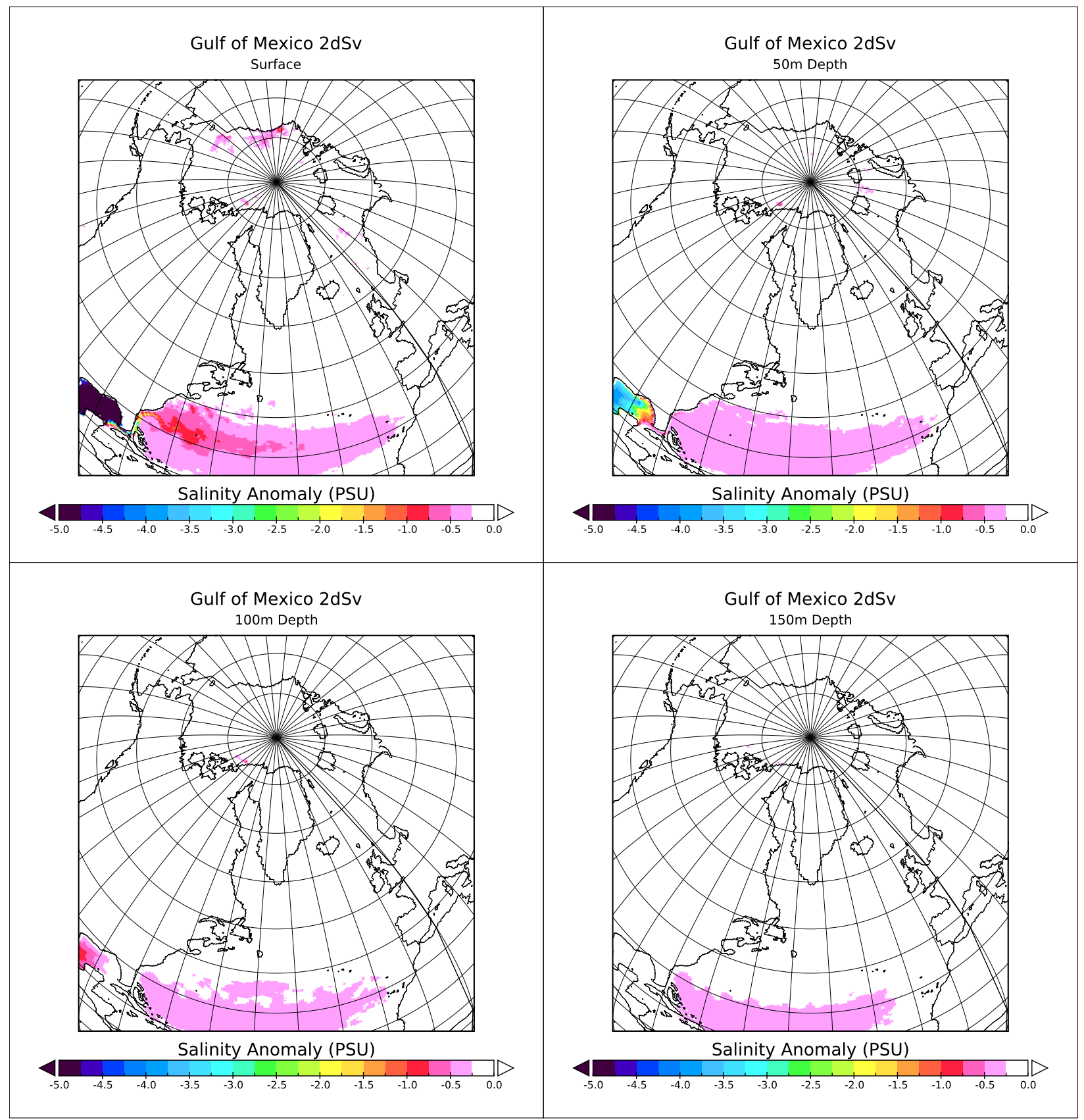

Figure S10: Salinity anomaly distribution at a selection of depths for the Open Bering Strait Gulf of Mexico 2dSv continual injection scenario. This distribution is the average of the anomaly field over the last 5 years of model integration. 


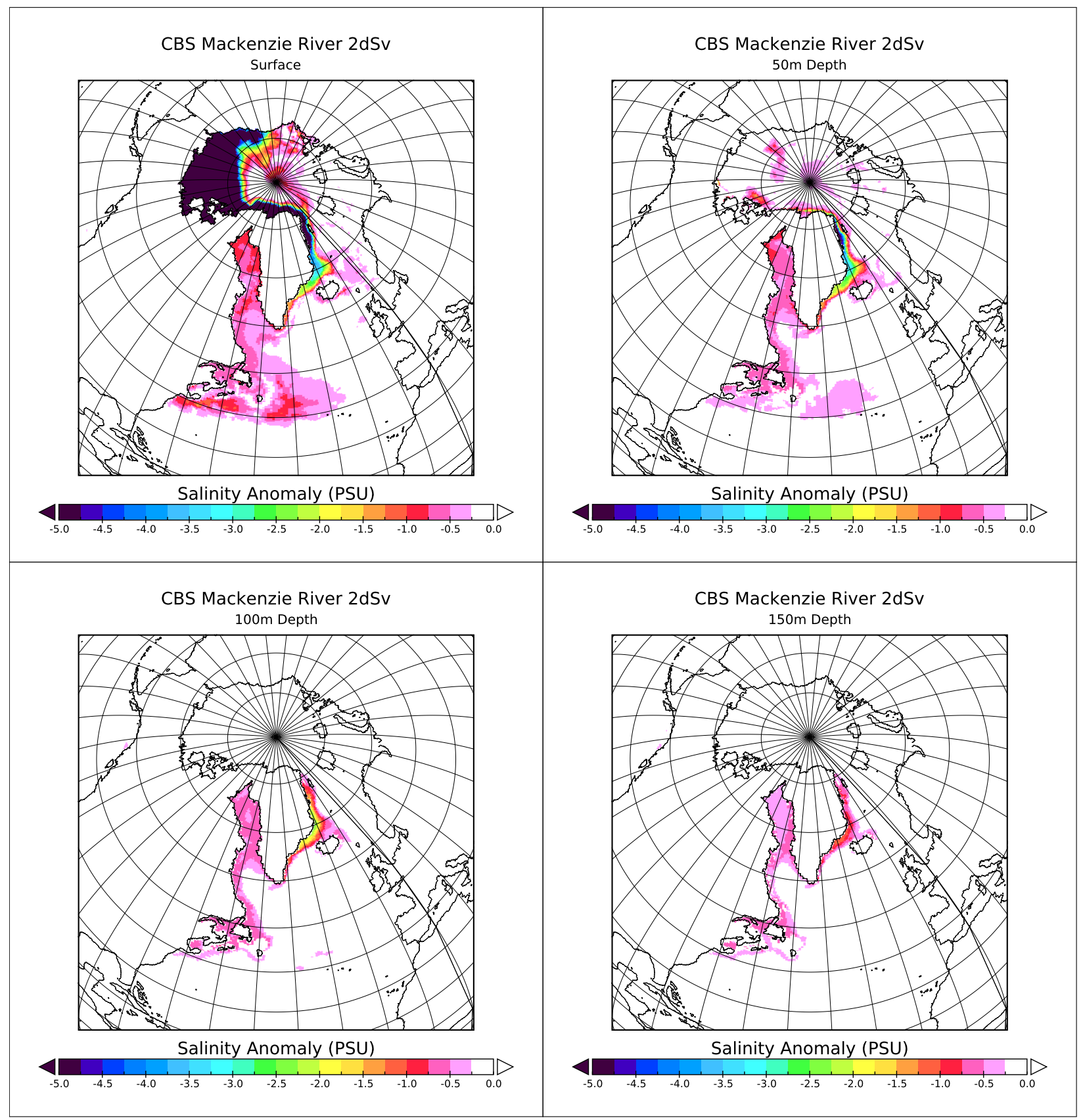

Figure S11: Salinity anomaly distribution at a selection of depths for the Closed Bering Strait Mackenzie River 2dSv continual injection scenario. This distribution is the average of the anomaly field over the last 5 years of model integration. 


\section{Model Drift}

For this isolated region we observe a maximum drift of $\approx 0.75 \mathrm{psu} / \mathrm{a}$ for the open Bering Strait YD case and a maximum of $\approx 0.3 \mathrm{psu} /$ a for the closed Bering Strait YD case. The drift is calculated over the duration of the respective control run. This trend is observed in the region directly where the surface runoff is introduced into the model and only in the uppermost $\approx 50 \mathrm{~m}$ of the water column, with the greatest drift present in the surface layer. For the drift of $\approx 0.75 \mathrm{psu} /$ a for the open Bering Strait YD case the magnitude reduces by an order of magnitude at the $30 \mathrm{~m}$ depth. Elsewhere in the simulation the calculated trend is generally below $0.05 \mathrm{psu} / \mathrm{a}$, a trend which may be an artefact of the short run time and reflect ongoing longer timescale internal variability.

OBS Control Salinity Drift

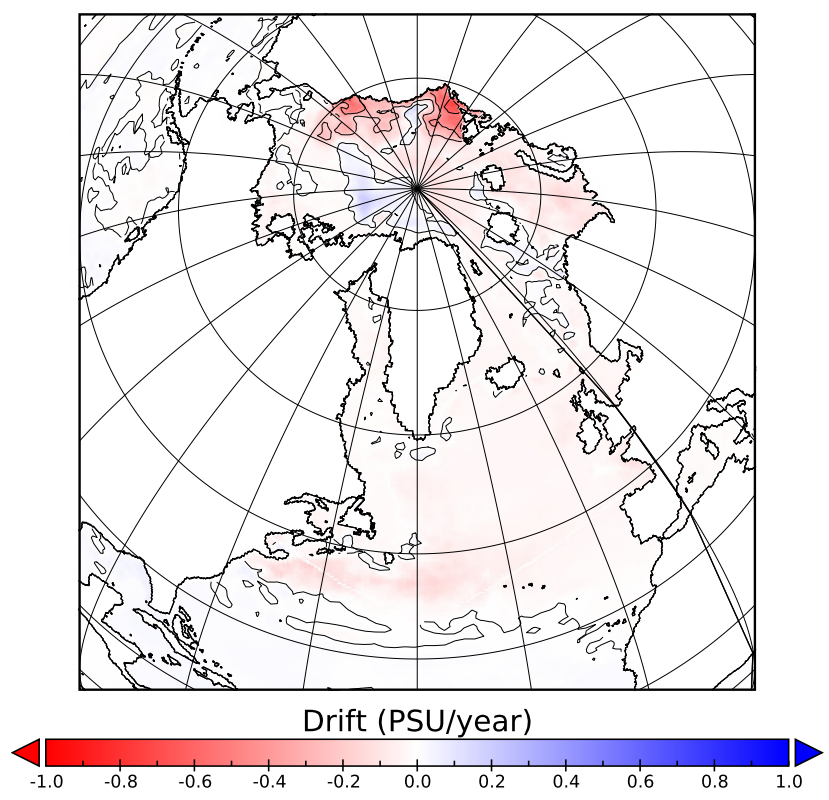

CBS Control Salinity Drift

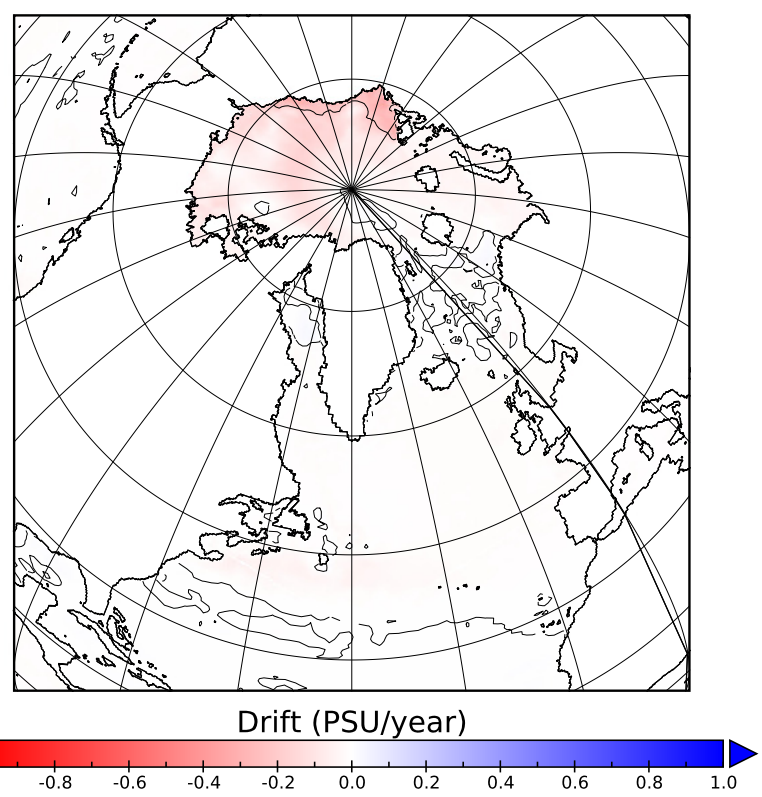

Figure S12: Drift for each of the control runs at the ocean surface calculated over the duration of the control run. Major scale intervals are contoured, most contours denote the 0-line. Continental outlines reflect the land-sea mask as used in each of the control simulations and are identical with the exception of the regions surrounding the Bering Strait. The drift is accounted for as part of the fingerprint processing routine. There is correspondence between the observed drift and the sources of runoff in the model boundary conditions, but is more noticeable in the open Bering Strait configuration. 


\section{References}

Lev Tarasov, Arthur S. Dyke, Radford M. Neal, and W.R. Peltier. A data-calibrated distribution of deglacial chronologies for the north american ice complex from glaciological modeling. Earth and Planetary Science Letters, 315316:30 - 40, 2012. ISSN 0012-821X. doi: http://dx.doi.org/10.1016/j.epsl.2011.09.010. URL http://www.sciencedirect. com/science/article/pii/S0012821X11005243. Sea Level and Ice Sheet Evolution: A $\{$ PALSEA $\}$ Special Edition. 